\title{
doispontos:
}

\section{Frankenstein e a vanguarda moral: Do império do direito ao domínio do judiciário}

\author{
Alessandro Pinzani \\ alepinzani@gmail.com \\ Professor do Depto de Filosofia da UFSC; pesquisador do CNPq.
}

Resumo: O artigo tece algumas considerações sobre o chamado constitucionalismo da efetividade ou neoconstitucionalismo, limitando-se, contudo a discutir seus aspetos teóricos, sem analisar casos concretos. Primeiramente são apresentados de forma sucinta os princípios centrais do neoconstitucionalismo, em particular na formulação de Luis Prieto Sanchís; em seguida, são avançadas algumas considerações a partir das observações de alguns dos seus críticos, em particular Juan García Amado. As teses destes dois autores são complementadas com algumas observações do autor e de outros autores, que insistem sobre aspectos relevantes para nossa discussão.

Palavras chaves: neoconstitucionalismo; constitucionalismo da efetividade; ativismo judicial; Prieto Sanchis; García Amado; corte constitucional

\begin{abstract}
The article offers some considerations about the so-called constitutionalism of effectiveness or neoconstitutionalism, limiting itself, however, to discussing its theoretical aspects, without analyzing specific cases. First, the central principles of neoconstitutionalism are briefly presented, particularly in the formulation offered by Luis Prieto Sanchís; then, some considerations are advanced starting from the remarks of some of its critics, in particular Juan García Amado. The theses of these two authors are complemented with some observations by the author and by other authors, who have touched on aspects that are relevant for our discussion.
\end{abstract}

Keywords: neoconstitutionalism; constitutionalism of effectiveness; judicial activism; Prieto Sanchis; García Amado; constitutional courts 
Neste artigo gostaria fazer algumas considerações sobre um fenômeno que está entre os mais discutidos das últimas décadas e que foi definido de várias maneiras, algumas quase derrogatórias (decisionismo ou ativismo judicial), outras mais neutras ou até positiva (constitucionalismo da efetividade ou neoconstitucionalismo - termo que não indica somente uma teoria jurídica, mas uma práxis judicial). Como se trata, justamente, de um fenômeno já amplamente debatido, limitar-me-ei a algumas considerações que podem ser marginais, do ponto de vista da teoria e da práxis jurídicas, mas possuem certa relevância do ponto de vista da filosofia política. Portanto, limitar-me-ei a discutir teorias e não analisarei casos concretos, ainda que de vez em quando possa servir-me de exemplos concretos. Minha preferência para discutir uma teoria em vez de realizar um diagnóstico do presente se deve à circunstância de que já houve autores que se ocuparam desta última tarefa e ao fato de que a teoria em questão teve, a meu ver, um papel fundamental nas atitudes tomadas por boa parte do judiciário brasileiro nos últimos anos e foi usada por ministros do STF para justificar algumas decisões centrais, como a relativa ao pedido de Habeas Corpus do presidente Lula.

Apresentarei primeiro de forma sucinta aqueles que me parecem ser os princípios centrais do neoconstitucionalismo, para, em seguida, fazer algumas considerações a partir das observações de alguns dos seus críticos. Entre as inúmeras formulações das posições neoconstitucionais (Comanducci, Barroso, Zagrebelsky, Carbonell), me servirei daquela oferecida por Luis Prieto Sanchís, que deu origem a um interessante debate com Juan García Amado (agora em CARBONELL, 2007). Assim, numa breve análise das duas posições poderemos entender o que está em jogo. Ao mesmo tempo, complementarei as teses destes dois autores espanhóis com algumas observações minhas e de outros autores, que insistem sobre aspectos relevantes para nossa discussão.

\section{1) O que é neoconstitucionalismo}

O conceito de constituição está em disputa, como todo conceito político. A própria atividade jurisdicional depende diretamente da maneira, na qual os juízes o entendem. Por isso, é problemático considerar tal atividade como se representasse um fenômeno unitário, como se se tratasse de uma ação que obedece a uma única intenção, como se houvesse um único sujeito chamado "o judiciário". Nas últimas décadas, contudo, houve no Brasil a prevalência de certa maneira de entender a ação dos juízes, visão que encontrou sua base teórica mais robusta no neoconstitucionalismo. Por mais que esta teoria (e prática) jurídica não seja a única, nem sequer a mais difundida no âmbito judicial brasileiro, me parece reunir todos os aspectos que caracterizaram de forma mais marcante a atividade dos juízes brasileiros que tentaram libertar-se das rédeas que lhes impusera uma leitura positivista restrita, dominante por muito tempo no Brasil. E, como frequentemente acontece, passou-se de um extremo para o outro.

Antes de discutir as características centrais do neoconstitucionalismo, porém, cabe fazer algumas considerações sobre as diferentes maneiras de pensar o próprio conceito de constituição. Para isso, recorrerei a um autor neo-constitucionalista, justamente para entender melhor o que esta teoria entende por constituição. O autor em questão é Paolo Comanducci. Comanducci (2007) identifica quatro modelos de constituição, ou seja, quatro maneiras diferentes de conceber o que é uma constituição; a cada um deles corresponde uma diferente maneira de pensar a ação do judiciário e a atividade de controle de constitucionalidade, mas não me ocuparei disso aqui.

Os quatro modelos se distinguem entre si ao longo de duas questões centrais: a constituição pode ser vista como ordem ou como norma; o modelo pode ser descritivo ou axiológico. Disso resultam as seguintes quatro possibilidades: 


\begin{tabular}{|c|c|c|}
\hline Tipo de modelo & Descritivo & Axiológico \\
\hline Constituição como & Modelo descritivo da & $\begin{array}{c}\text { Modelo axiológico da } \\
\text { constituição como ordem }\end{array}$ \\
\hline Norma & $\begin{array}{c}\text { Modelo descritivo da } \\
\text { constituição como norma }\end{array}$ & $\begin{array}{c}\text { Modelo axiológico da } \\
\text { constituição como norma }\end{array}$ \\
\hline
\end{tabular}

No modelo descritivo da constituição como ordem, esta é vista como um conjunto de fenômenos sociais que define a estrutura fundamental da sociedade e do Estado, sem possuir nenhum valor intrínseco ou gerar normas. Ela diz como se organizam os poderes públicos e quais são suas relações com os cidadãos e com os atores da sociedade civil. Nas palavras de Michel Troper (apud COMANDUCCI, 2007, p. 49), a constituição não pertence ao mundo do sollen (do dever ser), mas àquele do sein (do ser).

No modelo axiológico da constituição como ordem, os fenômenos sociais em questão possuem valor intrínseco e geram normas. Como exemplos, Comanducci cita Carl Schmitt, para o qual a constituição consiste em uma "decisão total sobre a espécie e a forma da união política" (apud COMANDUCCI, 2007, p. 46), e Costantino Mortati, que introduziu a noção de constituição material para distingui-la daquela positiva ou formal. Nesta visão, a própria ordem social possui uma normatividade intrínseca, que se reflete na sua atividade de produção de normas. A constituição é expressão da cultura e dos valores de um povo. É a visão típica de autores tradicionalistas ou contrarrevolucionários como Burke e de Maistre, mas também dos juristas nazistas, que, em seu afã antipositivista, fundamentavam suas decisões, que frequentemente iam contra as leis e a constituição de Weimar, apelando para princípios morais supra-positivos como a sã eticidade do povo alemão (cf. PAUER-STUDER e FINK, 2014; MAUS, 2018).

O modelo descritivo da constituição como norma considera a constituição como um texto normativo específico, a chamada constituição formal: um conjunto de normas que regulamenta a própria produção jurídica de leis ou organiza as instituições políticas etc. Este talvez seja o modelo mais utilizado na literatura constitucional, particularmente, mas não exclusivamente pelo positivismo jurídico em suas diferentes acepções, de Kelsen a Hart.

O modelo axiológico da constituição como norma é característico, entre outros, do neoconstitucionalismo. Neste modelo "toda a legislação é entendida como atuação da constituição e é interpretada à luz da constituição" (COMANDUCCI, 2007, p. 52). Sobre tudo, porém, nele a distinção entre sein e sollen, entre ser e dever ser, se enfraquece a ponto de desaparecer.

Para melhor entendermos este quarto modelo, que é o que nos interessa, passemos a considerar as seguintes teses que, na reconstrução de Carlos Bernal Pulido (2007, p. 290), caracterizam o neoconstitucionalismo na versão de Luis Prieto Sanchís:

1. A constituição é material, ou seja, possui um "denso conteúdo substantivo" (PRIETO SANCHÍS, 2007, p. 213), expressado primaria, mas não exclusivamente no conteúdo lingüístico do texto constitucional. Não se trata, em suma, de um texto que se limita a estabelecer regras formais para a produção legítima de direito positivo, como no modelo descritivo da constituição como norma. 
2. A constituição é garantida, isto é, é protegida pelos juízes. Em alguns países, isso acontece através de um tribunal específico, como o Tribunal Constitucional Federal alemão; em outros através de um tribunal que não exerce somente a atividade de controle de constitucionalidade, mas serve como suprema instância judicial; em outros através da ação de juízes em todos os níveis decisórios, inclusive os mais baixos na hierarquia judicial, como os tribunais de primeira instância; em outros países, enfim, a constituição é garantida pela ação conjunta do poder judiciário e do poder legislativo ou pelo próprio poder legislativo, como no Reino Unido. Esta pluralidade de opções dificulta em parte a elaboração de uma teoria unificada e aponta para certo caráter pragmático do neoconstitucionalismo. Cabe lembrar que os países, nos quais é previsto o controle constitucional através de um órgão judiciário, são, geralmente, países saídos de uma experiência totalitária ou ditatorial, como Itália, Alemanha ou Brasil. Sua introdução no texto constitucional, contudo, foi pensada primariamente para a defesa dos direitos fundamentais dos indivíduos contra os possíveis excessos do estado, ou seja, como uma tarefa "passiva" de proteção, não como uma tarefa "ativa" de definição e implementação de novos direitos ou de ampliação dos existentes. Por exemplo, a Corte Constitucional italiana é muito menos "ativa" ou propositiva do que o STF brasileiro.

3. A constituição é onipresente e irradia todo o sistema jurídico: "não há espaços isentos para o legislador, pois todos os espaços aparecem regulamentados" (PRIETO SANCHÍS, 2007, p. 218) Para usar uma expressão de Riccardo Guastini (2002) retomada por vários autores, a constituição é invasora ou intrometida, pois invade várias esferas (social, política, econômica etc.). Ou, para parafrasear um ditado clássico, quod non est in constitutione, non est in mundo (JESTAEDT, 2011, p. 87).

4. A constituição estabelece uma regulamentação principialista e, portanto, admite a possibilidade de conflitos ou colisões entre suas normas; produz, em suma, uma pluralidade de "mundos constitucionalmente possíveis" (J.J. Moreso apud PRIETO SANCHÍS, 2007, p.218). Por isso ela é considerada uma constituição viva, em contínua mudança.

5. A constituição se aplica mediante a ponderação, que permite estabelecer uma hierarquia entre princípios que entram em colisão.

6. Rechaça-se o modelo "geográfico" da relação entre constituição e legislação, pelo qual existe uma clara fronteira entre as duas: ou um caso é legal, ou é constitucional. Afirma-se, em lugar disso, um modelo argumentativo de relações entre constituição e legislação, pelo qual "não há problema jurídico que não possa ser constitucionalizado, e isso significa que deve ser descartada a existência de um mundo político separado ou imune da influência constitucional" (PRIETO SANCHÍs, 2007, p. 221).

Outro ponto essencial do neoconstitucionalismo, salientado por Prieto Sanchís é o do caráter transformador do direito, pois ele visa chegar a uma "constituição transformadora que pretende condicionar de modo importante as decisões da maioria, mas cujo protagonismo fundamental não corresponde ao legislador, senão aos juízes" (PRIETO SANCHÍS, 2003, p. 127). Isso implica, nas palavras de um neoconstitucionalista brasileiro, Eduardo Moreira, numa "maior presença judicial no lugar da autonomia do legislador" (MOREIRA, 2008, p. 38). Portanto, nas palavras do mesmo autor, "passamos de um direito em que as normas ditam o que fazer para um direito em que os princípios indicam o que se pode fazer" (MOREIRA, 2008, p. 18). O neoconstitucionalismo é assim "uma teoria do direito preocupada em transformar o que não deve ser e com a pretensão de corrigir aquilo que racionalmente pode ser aperfeiçoado (ideia do 'pode ser')" (ibidem) ou até com a pretensão de realizar certo resultado almejado, ainda que não sempre fique claro por quem: se pela própria constituição ou pelos juízes. Neste ponto, o neoconstitucionalismo se afasta da posição de Dworkin, que é considerado um dos seus mentores. Para Dworkin (2010), o poder judiciário deve ocupar-se exclusivamente com questões de princípios que surgem no contexto de um problema específico, deixando que questões teleológicas, isto é, questões de objetivos mais amplos, sejam 
resolvidas pelos órgãos de governo através de políticas públicas. Na hora em que o judiciário reclama para si a competência para realizar metas mais gerais (que podem ir da diminuição da injustiça social ao combate à corrupção), ele estaria extrapolando suas competências. Os neoconstitucionalistas, contudo, poderiam replicar que, às vezes, as metas estão explicitamente declaradas no texto constitucional, como acontece no caso da constituição de 1988 que, no preâmbulo e em alguns artigos, afirma almejar a criação de uma sociedade mais justa.

Finalmente, o neoconstitucionalismo defende que há algo como um "mais de direito", para servir-se de uma expressão usada pelo Tribunal Constitucional Federal alemão: "O direito não se identifica com a totalidade das leis escritas. Em certas circunstâncias, pode haver um 'mais' de direito [Mehr am Recht] em relação aos estatutos positivos do poder do estado, que tem sua fonte na ordem jurídica constitucional como uma totalidade de sentido e que pode servir de corretivo para a lei escrita [...]. A tarefa da jurisdição pode exigir que encontre e realize em suas decisões através de um ato de conhecimento valorativo, no qual não faltam elementos decisionistas [como já afirmava Schmitt, como vimos - A. P.], valores que são imanentes à ordem jurídica constitucional, mas que não chegaram a ser expressados nos textos das leis escritas ou o foram só parcialmente" (BVerfGE 34, 269ss. e 287; trad. parcial apud MOREIRA, 2008, p. 49; texto original apud MAUS, 2018, p. 118). Sempre o Tribunal Constitucional Federal afirma reconhecer "a existência de um direito supra-positivo que vincula também o poder legislativo constitucional, e possui a competência para julgar o direito positivo com base nele" (BVerfGE 1, 12, 32, apud MAUS, 2018, p. 28).

\section{2) As críticas de García Amado ao neoconstitucionalismo}

Passo agora a discutir algumas das críticas ao neoconstitucionalismo, em particular as de Juan García Amado. Como já disse, pretendo não somente expor, mas também ampliar tais críticas, que podem ser reunidas em três grupos temáticos que dizem respeito, respectivamente, a) à onipresença da constituição ou a seu caráter invasor, b) ao caráter anti-político e antidemocrático do neoconstitucionalismo e c) ao caráter metafísico da constituição, ou seja, ao fim da separação entre direito e ética.

\section{a) A onipresença da constituição}

A primeira crítica de García Amado a Prieto Sanchís é a de que este estaria confundindo o que a constituição diz com aquilo que seus intérpretes dizem que diz. A constituição diz somente o que dizem suas palavras e somente há três categorias de coisas: "a) coisas que a constituição diz claramente para exigi-las, proibi-las ou permiti-las (por exemplo: que a pena de morte está proibida em tempo de paz, como diz o artigo 15 da Constituição Espanhola); b) coisas sobre as quais não diz absolutamente nada (por exemplo: quantos animais domésticos posso ter em meu apartamento); c) coisas das quais não sabemos se diz algo ou não e, eventualmente, o que ela diz, pois isso depende de como interpretamos seus termines e enunciados (por exemplo: se um casal estável não casado ou homossexual é 'família' ou não e, portanto, merece a proteção dos poderes públicos exigida no artigo 39 da Constituição Espanhola" (GARCÍA AMADO, 2007, p. 238).

Prieto Sanchís ou outro neconstitucionalista poderia responder que, uma vez que a constituição é onipresente, ela regulamenta também as questões de tipo b) e c), ainda que não o faça de forma explícita (cf. BERNAL PULIDO, 2007, p. 292). Cabe aos juízes encontrar nela os princípios que permitam explicitar as normas jurídicas que regulamentam tais questões. Precisamente esta posição é alvo da crítica de García Amado (2007, p. 238), quando pergunta "de que modo está presente um mandato concreto em um enunciado constitucional semanticamente indeterminado". Segundo García Amado, que defende uma visão positivista, não existe na constituição nada mais do que está contido em suas palavras e não existem conteúdos pré-linguistícos (por exemplo, valores ou princípios que não sejam explicitamente mencionados no texto constitucional), como pensam os neoconstitucionalistas. Estes acabam projetando na constituição valores e princípios nos quais seus autores nunca pensaram. 
Ora, por um lado, esta operação de projeção pode fazer sentido, particularmente quando se trata de textos constitucionais escritos em outras épocas, como é o caso da constituição federal estadunidense de 1787. O risco de uma leitura "originalista" de tais textos (quer na vertente textualista, quer na vertente intencionalista) é o de condenar as gerações atuais a organizar seu ordenamento jurídico segundo valores que consideram ultrapassados ou inadequados às suas exigências. Seria o governo dos mortos sobre os vivos do qual já falava Thomas Jefferson (cf. CONSANI e PINZANI, 2013), que pensava em tempos muitos mais restritos, a saber, no espaço que separa uma geração da próxima: imagine-se se tivesse pensado em termos de séculos!

Por outro lado, o risco do originalismo é limitado a algumas poucas constituiçães e não é tão relevante para constituições mais recentes como a brasileira de 1988. Além disso, quando há um conflito de valores, como, por exemplo, no caso da definição do que é família, é sempre possível emendar por via legislativa o texto originário, introduzindo nele uma referência explícita a um valor ou a um princípio que não estavam presentes nele ou que o estavam de forma considerada inaceitável hoje. Afinal, o texto constitucional não é um texto sagrado (a constituição brasileira de 1988 já foi emendada mais de cem vezes). Os neoconstitucionalistas parecem oscilar entre esta visão da constituição como algo vivo, como um texto aberto e suscetível de modificações, por um lado, e, por outro, a tendência a estilizar-se como os únicos intérpretes confiáveis e autorizados do texto constitucional que, neste caso, assume um caráter fechado. É por isso que Ingeborg Maus, retomando uma expressão de Jürgen Seifert, fala de uma "teologia constitucional", na qual o texto constitucional é visto como um texto sagrado nos moldes da Bíblia ou do Alcorão, a partir do qual eruditos especializados "deduzem diretamente os valores e os comportamentos certos” (MAUS, 2018, p. 29). Em suma, conforme a ideia de uma onipresença da constituição, todo e qualquer caso jurídico estaria já previsto na constituição, explicita ou implicitamente; cabe aos seus intérpretes (aos juízes) trazer à tona a norma ou o princípio (escrito ou supra-positivo) que permitam resolvê-lo de vez.

b) O caráter anti-político e antidemocrático do neoconstitucionalismo

A segunda crítica de García Amado se dirige contra o caráter anti-político e antidemocrático do neoconstitucionalismo: Se a constituição não deixa espaços livres e se esta regulamentação, quando não for explícita, depende da interpretação do texto constitucional e da ponderação entre valores não explícitos por parte dos juízes, então, conclui García Amado, "não sobrará espaço para uma sociedade que exerça a política, e todos passaremos a ser súditos do supremo órgão político e não democrático, a saber, do judiciário" (apud BERNAL PULIDO, 2007, p. 294). O poder judiciário e não o parlamento democraticamente eleito é o verdadeiro legislador.

Para entendermos por que García Amado atribui caráter anti-político ao neoconstitucionalismo, devemos lembrar que a política é, primeira e primariamente, conflito e que o que caracteriza a política democrática é a busca pacífica de um acordo entre interesses divergentes sem que se tente afirmar a "verdade" ou a "justeza" de alguns deles e o caráter falso ou injusto dos demais. A política democrática não nega a divergência não componível dos interesses; se alimenta, antes, dela e só tenta impedir que o conflito se torne destrutivo do tecido social. O neoconstitucionalismo, pelo contrário, busca criar uma harmonia entre interesses e uma unidade social que não existem na realidade e que nunca poderão existir. Na busca de harmonizar o ser com o dever ser, acaba sacrificando o primeiro - ou melhor: acaba impondo à complexa realidade conflituosa da sociedade uma resolução dos conflitos que é unilateral e, portanto, acaba servindo somente um dos interesses em luta que, alem de resultar vencedor, é considerado como sendo o único legítimo. Pois, na lógica totalizante do neoconstitucionalismo, segundo a qual o direito deve ser entendido em sentido amplo, isto é, incluindo princípios morais presumidamente objetivos, para cada conflito existe uma e uma só resolução que deve ser encontrada ou diretamente no texto constitucional ou ponderando princípios 
que podem não estar presentes explicitamente nele. Conforme esta lógica, se houver um conflito entre interesses divergentes, somente as razões de um dos lados podem ser consideradas plenamente justificadas e devem, portanto, prevalecer. A resolução jurídica do conflito através da atribuição da "razão" a uma das partes prevalece assim sobre a formação do consenso político através do acordo de interesses conflitantes. A judicialização da política não representa uma nova forma de fazer política, mas a morte da política.

Neste processo, o juiz vira uma espécie de déspota esclarecido que impõe aos demais poderes e à sociedade uma paz social que somente ele enxerga com clareza. A figura do juiz se torna, assim, central - não somente pela sua posição no interior do sistema de pesos e contrapesos constitucionais, mas pelo fato de representar a consciência moral da sociedade. Isso pressupõe que ele possui uma personalidade moral superior à dos outros representantes das instituições, em particular dos membros do legislativo e do executivo; na realidade, acontece aqui uma inversão interessante: não é sua personalidade integérrima que lhe atribui o rotulo de consciência moral da sociedade; antes é sua posição de juiz que o eleva acima dos demais representantes e garante pela integridade moral de sua pessoa, independentemente de isso ser verdade ou não. Ele é integérrimo enquanto juiz, não juiz enquanto integérrimo. Voltarei a este ponto discutindo a relação entre direito e moral no neoconstitucionalismo.

O caráter anti-político do neoconstitucionalismo se manifesta particularmente na primazia atribuída por ele ao método da ponderação como instrumento de resolução dos conflitos jurídicos. Segundo García Amado (1996/97, p. 71), a ponderação é um procedimento irracional, pois não possui uma estrutura clara e não existe um "ponderómetro", isto é, "um critério intersubjetivo para determinar quando um princípio deve ser preferido a outro num caso concreto" (BERNAL POLIDO, 2007, p. 296). A ponderação acaba dando "aparência de legitimidade a um ativismo judicial" que viola "as competências do legislador e da jurisdição ordinária e que é incompatível com a democracia e o estado de direito" (BERNAL POLIDO 2007, p. 296). Ernst-Wolfgang Böckenförde, que foi juiz do Tribunal Constitucional Federal alemão, expressou uma ideia análoga ao dizer que estamos passando de um tipo de estado para outro, a saber, "do estado do poder legislador parlamentar para o estado do poder judiciário que realiza a constituição" (BÖCKENFÖRDE, 1981, p. 402).

Isso levanta um problema de legitimação que não se coloca no caso dos procedimentos parlamentares e que possui dois aspectos. O primeiro e mais óbvio tem a ver com o fato de que os membros do parlamento são democraticamente eleitos e os juízes dos tribunais que possuem o poder de controle constitucional não. Os membros dos tribunais constitucionais podem até ser nomeados por órgãos políticos eleitos como um presidente, um senado ou um parlamento, e, portanto, sua nomeação pode ser vista como expressão indireta da vontade política da maioria dos cidadãos, mas isso não vale para os juízes que são ativos em níveis inferiores e que, em alguns ordenamentos jurídicos, como o brasileiro, podem questionar a constitucionalidade de uma lei. E também no caso de juízes nomeados por órgãos políticos eleitos, seus cargos são normalmente vitalícios e não revogáveis. Esta medida, que visa torná-los imunes das pressões políticas e garantir a independência de seus juízos, acaba tornando-os, ao mesmo tempo, livres de dever qualquer prestação de conta ao povo soberano, que não tem como substituí-los, se não gostar de suas decisões, como acontece, pelo contrário, com governos e parlamentos. Enquanto os políticos eleitos assumem plenamente a responsabilidade de suas decisões e podem ser punidos pelos cidadãos, os juízes nunca são chamados a responder pelo resultado de suas ponderações, apesar dos altos custos econômicos e sociais que elas podem ter como conseqüência. Os únicos que poderiam rever tais decisões são os representantes eleitos, isto é, o parlamento: ou emitindo uma lei que regulamente de maneira diferente a questão decidida pelos juízes ou emendando a constituição, de maneira a solapar a base jurídica da decisão em questão. $O$ problema é que esta ação do legislativo pode ser submetida por sua vez ao controle de constitucionalidade exercido pelo judiciário, como acontece no Brasil, deixando que a última palavra fique com ele. De certa maneira, isso reforça o diagnóstico de Böckenförde: passamos de uma forma de estado, na qual a última 
palavra era a do legislador parlamentar, para uma, na qual ela está com o poder judiciário, que, assim, se torna o verdadeiro soberano (no sentido tradicional de potestas superiorem non recognoscens). $\mathrm{O}$ judiciário deixa de ser meramente o garante da lei, o defensor dos direitos fundamentais e o guardião da separação dos poderes inscrita na constituição. É isso que denomino de domínio do judiciário.

Alguém poderia observar que esta não é uma conseqüência necessária, uma vez que o poder judiciário estaria agindo justamente para garantir uma mais ampla e mais radical aplicação das proteções jurídicas garantidas pelo texto constitucional. Na realidade, isso vale para o garantismo (por exemplo na versão de Ferrajoli), que não coincide com o neoconstitucionalismo. É verdade que, geralmente, os neoconstitucionalistas são garantistas porque consideram os direitos fundamentais elencados nas constituições como expressões de princípios e valores que devem ser aplicados potencialmente em todos os casos jurídicos concretos. Contudo, a ponderação de princípios pode inclusive levar um juiz a reduzir um direito garantido pela constituição em nome de um valor ou um princípio que ele considera superior: a presunção de inocência, garantida pelo texto constitucional de 1988, por exemplo, pode ser considerada por um juiz neoconstitucionalista como um mero princípio, em vez de um direito ou de uma regra, e pode ser preterida em prol de outro princípio, como o da confiança no sistema jurídico, ainda que se trate de um princípio muito mais vago e de difícil definição - o que reforça a observação de García Amado de que não existe um ponderómetro e de que o método da ponderação corre o risco de levar a resultados arbitrários ligados às visões subjetivas dos juízes sobre o que conta como princípio e sobre sua presumida superioridade sobre outros princípios. Como afirma Ingeborg Maus: "As limitações dos direitos fundamentais são tomadas em cada caso por meio de uma ponderação de valores e sempre em consideração das circunstâncias particulares, ou seja, em outras circunstâncias poderiam também ser definidas de maneira diferente" (MAUS, 2018, p. 43). Assim, um dos pilares do estado de direito, a saber, a certeza jurídica, acaba sendo abalado uma vez que regras ou princípios explicitamente afirmados no texto constitucional passam a ser objeto de ponderação por parte de um juiz e podem ser preteridos por ele em prol de princípios que não estão no texto.

Contra esta acusação, os neoconstitucionalistas recorrem à ideia de derrotabilidade (cf. MOREIRA, 2008, p. 94): uma regra pode ser derrotada, em casos excepcionais, sem perder seu valor de regra. Se o juiz, ao avaliar os efeitos da regra (por exemplo, da regra da presunção de inocência), chegar à conclusão de que, no caso específico que está sendo examinado, eles são deletérios ou violam um ou mais princípios que ele considera valiosos, então, ele seria autorizado a considerar a regra como sendo "derrotada" por trais princípios, apesar de ela manter seu valor de regra para outros casos.

Ora, isso abre, mais uma vez, espaço para resultados arbitrários, particularmente nos casos, nos quais os juízes tomam suas decisões não no âmbito de um debate aberto com outros juízes, mas chegam às suas conclusões isoladamente, limitando-se a comunicá-las aos outros membros do tribunal na hora da leitura ou exposição de seus votos, como acontece no STF. A ponderação acontece tendo como único interlocutor o próprio juiz, sem que ele debata com os outros. Daí a inevitável impressão de discricionariedade que resulta do fato de diferentes juízes motivarem seus votos discordantes invocando princípios opostos ou até os mesmos princípios, mas invertendo sua hierarquia.

Ora, os neoconstitucionalistas reconhecem isso. Nas palavras de Zagrebelsky: "a discricionariedade é um dato insuperável” (2006, p. 6) nas decisões judiciárias, como nas políticas, e, por isso, não representa um problema. Isso, porém, seria verdade somente se as decisões tomadas discricionariamente pelos juízes pudessem ser modificadas com a mesma facilidade com a qual podem ser modificas as igualmente discricionárias decisões tomadas pelos governos e pelos parlamentos. Mas, como sabemos, isso não acontece tão facilmente. 
O segundo aspecto do problema de legitimação mencionado acima é menos óbvio do primeiro e está ligado ao caráter exclusivo do procedimento judicial (MÖLLERS, 2011, p. 318 ss.). Os juízes decidem sobre um caso individual, ouvindo somente as partes envolvidas, mas sua decisão pode afetar toda a comunidade jurídica, todos os cidadãos, sem que haja uma discussão ampla que represente todas as posições possíveis, como, geralmente, acontece nos parlamentos. Este caráter exclusivo se manifesta de maneira mais evidente nos casos, nos quais os juízes do tribunal em questão decidem monocraticamente ou, no caso de decisões de colegiado, sequer deliberam entre si, mas se limitam a manifestar suas opiniões na hora de tornar pública sua decisão, como vimos. Além disso, as decisões políticas podem ser revistas, quando mudar a maioria no legislativo, por ex. Uma decisão judicial alcançada com base em argumentos de princípios que se pressupõem racionais dificilmente será modificada, pois se o fosse, isso provocaria uma crise de confiança na capacidade de o tribunal em questão fundamentar racionalmente suas decisões ou até na sua imparcialidade e boa fé.

Estes problemas de legitimação apontam para o caráter antidemocrático do neoconstitucionalismo que, como veremos, alguns de seus defensores não somente reconhecem, como defendem abertamente. Sobre tudo, porém, revelam que o neoconstitucionalismo parte de uma visão dos conflitos sociais como meros conflitos jurídicos ou como conflitos entre diferentes princípios morais - conflitos que, portanto, podem ser resolvidos por meio de uma decisão judicial unívoca. Mais uma vez: se uma das partes sai vencedora do procedimento jurídico, se seus interesses são reconhecidos como sendo os únicos que possuem fundamentação jurídica ou moral suficiente, os interesses das partes derrotadas são eo ipso declarados ilegítimos jurídica e moralmente - ao contrário do que acontece quando a resolução do conflito é política e se dá pela atividade legisladora do parlamento. $O$ conflito social acaba se transformando em um jogo a soma zero, no qual uma parte ganha e outra perde, sem possibilidade de um acordo de mediação, no qual as partes vão uma ao encontro da outras. Isso muda no caso em que se recorra a uma arbitragem ou a outros métodos alternativos de resolução das controvérsias que, contudo, me parecem ir contra as intenções e as intuições do neoconstitucionalismo, pois sinalizam antes uma tendência a tratar todas as questões jurídicas como questões não de direito constitucional, mas de direito privado, de direito contratual ou de Tort Law - tendência que pode por sua vez resultar no uso do direito como instrumento para opor-se a decisões tomadas democraticamente (para este uso foi cunhado o termo de lawfare, como se sabe).

\section{c) A constituição metafísica e a fim da separação entre direito e ética}

Finalmente, voltando à crítica de García Amado a Prieto Sanchís, ao pressupor que a constituição forma "um sistema axiológico pleno e coerente que subjaz ao texto constitucional e é independente dele", o neoconstitucionalismo defende a existência de uma constituição metafísica, que "prescreveria uma única resposta para cada caso possível”, tornando supérfluo o texto constitucional positivo (BERNAL POLIDO, 2007, p. 97). O risco é que se afirme a ideia de uma constituição universal que independe do texto constitucional específico - ideia que parece revelar-se na tendência crescente das cortes constitucionais em servir-se de decisões tomadas por tribunais análogos de outros países, que possuem outra constituição. Este fenômeno levou inclusive, nos Estados Unidos, a uma proposta de lei (o Constitution Restoration Act) que proibiria o uso de documentos jurídicos, leis ou sentenças de outros países por parte dos juízes estadunidenses.

Deste ponto de vista, o que os críticos do neoconstitucionalismo consideram extremamente problemático é a inclusão de princípios morais no direito, pois isso teria como conseqüência o desaparecimento de espaços livres de regulamentação jurídica num sentido mais forte do que já acontecia com a afirmação da onipresença da constituição (MAUS, 2018, p. 15). Já que toda e qualquer esfera de ação humana pode ser objeto de princípios morais, se estes forem incluídos no direito, tudo se torna um possível objeto de regulamentação jurídica. Lembro, como exemplo extremo disso, o caso daquele juiz do Rio Grande do 
Sul que condenou um pai por não ter amado bastante o filho, como se o amor paterno pudesse ser objeto de normas jurídicas e pudesse ser objeto de coerção jurídica (o pai foi condenado a pagar indenização ao filho). O judiciário se transforma assim em instância moral suprema da sociedade e, portanto, se põe mais uma vez acima de todos os outros poderes públicos. Para usar uma expressão da Maus, o judiciário virou uma espécie de Super-Ego da sociedade (2018) ou, para usar a expressão derrogatória de Posner (2005, p. 99), os juízes passam a se ver como a "vanguarda moral" da sociedade - expressão ecoada pelo mais conhecido neoconstitucionalista brasileiro, Luis Roberto Barroso, quando usa - mas positivamente! - o termo "vanguarda iluminista" (BARROSO, 2015, p. 42).

Defensores da posição neoconstitucionalista poderiam afirmar que os princípios e valores que constituem o que o Tribunal Constitucional Federal alemão chama de "mais de direito" ou de direito supra-positivo não são universais e absolutos, mas são próprios de determinada sociedade, ou melhor, de determinada comunidade jurídica e política. O problema, porém, consiste na identificação de tais valores. Qual é a relação entre as convicções morais que, empiricamente, são dominantes numa sociedade, por um lado, e as convicções morais do juiz, pelo outro?

Sabemos que este é o punctum dolens das teorias que defendem a inclusão de princípios morais no direito, como, por exemplo, no caso da teoria de Dworkin. Faço um exemplo: o direito de adoção para casais homossexuais. Se o STF for chamado a julgar sobre isso e seus juízes resolverem decidir a questão com base numa ponderação puramente principialista, servindo-se de princípios morais, apelariam para princípios universais como a da inadmissibilidade de discriminações fundadas na orientação sexual? Ou se orientariam antes pelo sentimento moral majoritário no Brasil que, provavelmente, consideraria inaceitável esta forma de adoção? Obedece-se a princípios morais universais ou a convicções morais locais? À razão prática ou ao sensus moralis communis de determinada comunidade jurídica? Se os juízes optarem por esta segunda possibilidade, estariam defendendo um modelo axiológico da constituição como ordem - o clássico modelo dos pensadores conservadores ou reacionários, defensores da visão de que o status quo social, político e moral é expressão da cultura nacional e possui valor intrínseco (fundamentalmente, o argumento com o qual se defendeu em vários países europeus a legitimidade de colocar símbolos cristãos nos espaços públicos como aula de escola ou de tribunal). Se nossos juízes optarem pela primeira possibilidade e se orientassem por princípios universais, estariam defendendo o modelo axiológico da constituição como norma, típico do neoconstitucionalismo, mas a preço de afastar-se notavelmente da opinião moral dominante na sociedade. Não que isso seja necessariamente um mal, particularmente em casos, nos quais o que está em jogo é a extensão de direitos a indivíduos que até o momento foram excluídos do gozo deles. Ao mesmo tempo, contudo, isso reforçaria a ideia de que os juízes buscam uma solução antidemocrática, adotando uma postura anti-política e, sobre tudo, erguendo-se como suprema autoridade moral da sociedade.

Esta superioridade moral do juiz parece ser um pressuposto inevitável do neoconstitucionalismo. Gustavo Zagrebelsky, falando da justiça constitucional, afirma: "sua natureza marcadamente supra-estrutural, expressão de exigências que se separam do sentimento popular imediato e da interpretação que dele fazem os órgãos políticos, expõe sempre os tribunais à contestação da legitimidade de suas decisões, de sua composição e, em caso de forte contraste, inclusive da sua existência" (2006, p. 6). O que interessa aqui é o fato de Zagrebelsky ressaltar positivamente a distância que separa o sentimento popular das decisões dos juízes. Zagrebelsky, que foi - cabe lembrar - membro e presidente da Corte Constitucional italiana, defende indiretamente a necessidade de manter tal distância, quando aponta para o caráter republicano e não democrático das constituições, inclusive a italiana de 1948. O que diferencia a república da democracia é o fato de que, na primeira, o poder decisório do povo não é ilimitado. Nas palavras do justice Robert Jackson em West Virginia Board of Education vs. Barnette (1943), citadas por Zagrebelsky, "o autentico propósito de uma constituição [...] é o de subtrair certas matérias às vicissitudes das controvérsias políticas 
[percebe-se aqui certa polêmica anti-política - A. P.], colocá-las fora do alcance de maiorias e funcionários públicos, sancioná-las como princípios legais aplicáveis pelos tribunais. O direito de cada um à vida, à liberdade, à propriedade, a liberdade de expressão, a liberdade de imprensa, a liberdade de culto e de reunião e os demais direitos fundamentais não podem ser submetido ao voto; não dependem do êxito de nenhuma votação" (apud ZAGREBELSKY 2006, p. 11). Deste ponto de vista, afirma Zagrebelsky, "a justiça constitucional é função da república, não da democracia" (ibidem).

Na realidade, estas afirmações poderiam ser compartilhadas também pelos defensores de um modelo descritivo da constituição como norma e até de um modelo descritivo da constituição como ordem, pois, afinal, a maioria - se não a totalidade - das constituições elaboradas no segundo pós-guerra subtraem explicitamente os direitos individuais fundamentais das decisões majoritárias, por mais que isso não sempre aconteça de forma automática: instituir um referendum para abolir o casamento gay ou para impedir que ele se torne legal, como aconteceu em vários países nos últimos anos, é um exemplo de como, infelizmente, nem todos os direitos são subtraídos à vontade da maioria e de como nem todos os cidadãos são considerados legalmente iguais. Neste ponto, os neoconstitucionalistas têm jogo fácil em apontar para a necessidade de subtrair as decisões concernentes os direitos fundamentais da vontade popular e atribuí-las, antes, aos tribunais.

O problema é que esta solução não garante que nas cortes não aconteçam as mesmas discriminações. Afinal, nem sempre a decisão dos tribunais constitucionais é tomada por unanimidade. Particularmente nos casos moral ou politicamente polêmicos, a decisão é tomada por maioria e, frequentemente, por uma maioria muito restrita: dependendo do número dos juízes, por 5 a 4, por 6 a 5 etc. A impressão é de que, nesses casos, o tribunal atuou como um pequeno parlamento, como reconhece Zagrebelsky, e que as convicções éticas ou políticas individuais dos juízes prevaleceram sobre a preocupação republicana para com a defesa dos direitos individuais. Temos inúmeros exemplos históricos disso: só citarei as diferentes decisões da Corte Suprema estadunidense em relação à legitimidade da escravidão ou das leis de segregação racial. Zagrebelsky tenta nos convencer de que ainda assim haveria uma diferença entre parlamento e corte constitucional: "a discricionariedade como expressão da vontade que se impõe, própria dos órgãos políticos, é uma coisa distinta da discricionariedade 'republicana', dirigida ao consenso sobre a constituição" (2006, p. 12). Confesso, contudo, que não consigo enxergar com muita clareza a distinção, particularmente se eu for levar em conta decisões tomadas por vários tribunais constitucionais, inclusive pelo STF brasileiro - decisões que parecem refletir a posição política ou moral pessoal dos juízes mais do que um genuíno interesse republicano.

O problema do modelo neoconstitucionalista é que ele poderia funcionar somente se tivéssemos a garantia de que os juízes fossem todos como o juiz Hercules de Dworkin e conseguissem, de fato, tomar suas decisões de maneira absolutamente imparcial, levando em conta os princípios morais relevantes (supondo que eles consigam identificá-los, em primeiro lugar). A realidade empírica nos apresenta, contudo, um quadro da situação bem diferente. A presumida moralização do direito (que, como vimos, já é problemática), esconde uma politização do judiciário que é mais problemática ainda. De maneira cada vez mais freqüente, surge a impressão de que os juízes tomem decisões puramente políticas, e o façam entrincheirando-se atrás de princípios morais arbitrariamente escolhidos entre uma miríade de princípios igualmente validos e que poderiam ter sido igualmente chamados em causa para justificar decisões diferentes ou até opostas. Estamos perante uma forma inédita de lawfare: a própria constituição é invocada para revogar decisões tomadas democraticamente, para remover do seu cargo oficiais democraticamente eleitos apesar da inexistência de fundamentos jurídicos para tanto, ou para retirar direitos fundamentais de devido processo a alguns cidadãos, enquanto eles ficam garantidos para outros. Estas decisões políticas nos são apresentadas como decisões puramente jurídicas ou, pior, como decisões fundamentadas moralmente, tomadas por indivíduos que se consideram a vanguarda moral do país. Duvido que esta fosse a intenção do constituinte na hora 
de introduzir o mecanismo do controle constitucional, mas os neoconstitucionalistas me acusariam, provavelmente, de ser um originalista da vertente intencionalista, ao defender esta posição.

A constituição criou o poder judiciário para se defender contra possíveis ataques autoritários. O problema é que o judiciário parece ter-se transformado na criatura de Frankenstein: criada nas melhores intenções, mas fadada a provocar a infelicidade e, finalmente, a destruição de seu criador.

\section{Referências}

BARROSO, L. R. 2015. A razão sem voto. O Supremo Tribunal Federal e o governo da maioria. Revista Brasileira de Políticas Públicas, 5, 24-50.

BERNAL PULIDO, C. 2007. Refutación y defensa del neoconstitucionalismo. In: CARBONELL, M. (ed.). Teoría del neoconstitucionalismo. Ensayos escogidos. Madrid: Trotta, 289-325.

BÖCKENFÖRDE, E.-W. 1981. Gesetz und gesetzgebende Gewalt. Von den Anfängen der deutschen Staatsrechtslehre bis zur Höhe des staatsrechtlichen Positivismus. 2. Aufgabe. Berlin: Duncker \& Humblot.

COMANDUCCI, P. 2007. Modelos e interpretación de la constitución. In: CARBONELL, M. (ed.). Teoría del neoconstitucionalismo. Ensayos escogidos. Madrid: Trotta, 41-67.

CONSANI, C. F.; PINZANI, A. 2013. Jefferson vs. Madison Revised. Jahrbuch für Recht und Ethik / Annual Review of Law and Ethics. Bd. 21: Das Rechtsstaatsprinzip / The Rule of Law-Principle, 111-132.

DWORKIN, R. 2010. Levando os direitos a sério. $3^{\mathrm{a}}$ edição. São Paulo: Martins Fontes.

GARCÍA AMADO, J. A. 1996/97. ¿Ductilidad del derecho o exaltación del juez? Defensa de la ley frente a (otros) valores y principios. Archivo de Filosofía del Derecho, XIII-XIV, 65-85.

GARCÍA AMADO, J. A. 2007. Derechos y pretextos. Elementos de crítica del neoconstitucionalismo. In: CARBONELL, M. (ed.). Teoría del neoconstitucionalismo. Ensayos escogidos. Madrid: Trotta, 237-264.

GUASTINI R. 2002. La "costituzionalizzazione” dell'ordinamento giuridico. In: MAZZARESE, T. (ed.), Neocostituzionalismo e tutela (sovra)nazionale dei diritti fondamentali. Torino: Giappichelli, 147-172.

JESTAEDT, M. 2011. Phänomen Bundesverfassungsgericht. Was das Gericht zu dem macht, was es ist. In: JESTAEDT, M.; LEPSIUS, O.; MÖLLERS, Ch.; SCHÖNBERGER, Ch. Das entgrenzte Gericht. Eine kritische Bilanz nach sechzig Jahren Bundesverfassungsgericht. Berlin: Suhrkamp, 77-157.

MAUS, I. 2018. Justiz als gesellschaftliches Über-Ich. Zur Position der Rechtsprechung in der Demokratie. Berlin: Suhrkamp.

MÖLLERS, Ch. 2011. Legalität, Legitimität und Legitimation des Bundesverfasssungsgerichts. In: JESTAEDT, M.; LEPSIUS, O.; MÖLLERS, Ch.; SCHÖNBERGER, Ch.. Das entgrenzte Gericht. Eine kritische Bilanz nach sechzig Jahren Bundesverfassungsgericht. Berlin: Suhrkamp, 281-422.

MOREIRA, E. R. 2008. Neoconstitucionalismo. A invasão da constituição. São Paolo: Método.

PAUER-STUDER, H.; FINK, J. (Hrsg.) 2014. Rechtfertigungen des Unrechts. Das Rechtsdenken im Nationalsozialismus in Originaltexten. Berlin: Suhrkamp. 
POSNER, R. 2005. The Supreme Court, 2004 Term - Foreword: A Political Court. Harvard Law Review, $119,32-102$.

PRIETO SANCHÍS, L. 2003. Neoconstitucionalismo y ponderación judicial. In: CARBONELL, M. (ed.). Neoconstitucionalismo(s). Madrid: Trotta, 123-158.

PRIETO SANCHÍS, L. 2007. El constitucionalismo de los derechos. In: CARBONELL, M. (ed.). Teoría del neoconstitucionalismo. Ensayos escogidos. Madrid: Trotta, 213-235.

ZAGREBELSKY, G. 2006. Le Corti costituzionali, le Costituzioni democratiche, l'interdipendenza el'indivisibilità dei beni costituzionali. Discorso pronunciato in Campidoglio per la celebrazione dei 50 anni di attività della Corte costituzionale - Roma, 22 aprile 2006 Acessível em: http://www.astrid-online.it/static/ upload/protected/Zagr/Zagrebelsky_Repubblica_22apr2006.pdf (acessado em 30/04/2020) 